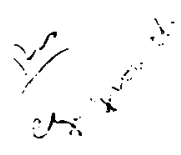

\title{
THE GROWTH RATE OF RAINBOW TROUT FROM SOME MICHIGAN WATERS
}

\author{
John R. GreELEY \\ Institute for Fisheries Research, University of Michigan
}

Ages of 329 rainbow trout from Michigan streams and lakes were determined by study of the scales. All but twenty-two specimens were from streams of western Michigan (Lake, Manistee and Newaygo counties). The fish ranged in size from 1.75 to 31.0 inches (total length) and represented both adult stages (97 individuals) and immature stages (232 individuals). By means of seining, angling, and trapping of fish ascending to spawn, some individuals of every age group up to seven winters were obtained. The material was collected during 1928 (1 specimen), 1930 (200 specimens), 1931 (116 specimens), and 1932 (12 specimens) and includes fish taken in April, May, June, July and August. The largest series of scales of adult fish from any one locality was obtained from wild-trapped fish held at the Manistee spawn-taking station of the State Department of Conservation. Measurements and scales were taken from sixtysix fish, representative of size ranges in a much larger number, without apparent injury to the fish. The material studied included scale samples obtained through cooperation of anglers, Department of Conservation field men, and the U. S. Bureau of Fisheries.

Scales were mounted in glycerine jelly and were studied with a projection microscope having a ground-glass screen. Measurements of anterior field (from focus of scale out toward the margin) were taken for use in computing fish lengths at various years of life.

\section{Migratory and Non-Migratory Rainbows}

Field work on Michigan trout streams has clearly indicated that some rainbow trout remain in streams until mature, presumably throughout their lives, while others migrate to a large lake (usually Lake Michigan) before maturity. Adult or maturing non-migratory specimens from the Pigeon River and Ontonogon River are included in the material studied. Most of the specimens from other localities, especially those from the Manistee and other streams of western Michigan, belong to the migratory category.

The rainbows with non-migratory life-history appear indistinguishable from those of migratory habit, when young fish are compared. Adults of the migratory type are commonly larger than the stream-resident fish of the same age. The breeding coloration in both types is essentially alike.

The silvery or "steelhead" coloration in migratory fish is more pronounced than in non-migratory individuals. The immature fish, analogous to the "parr" of salmon, are alike in both types. Fish 
with the non-migratory type of life-history apparently change to the adult stage without a conspicuous intervening phase. Those with the migratory type of life-history, on the other hand, pass through a stage analogous to the "smolt" phase of the salmon. They become bright silvery and the parr marks are obscured. The round, black spots are also more or less obscured and many tend to become $\mathrm{X}$-shaped. The dorsal fin and caudal fin become darker. The silvery fish, very different from its former coloration, is often thought by anglers to be a different species, and is called a "steelhead." Migration takes place at or near the time of transformation. Some individuals transform during the fall months, while others transform as late as May.

Ichthyologists have different opinions in regard to the number of recognizable forms of rainbow trout, and the scientific names to be used for such forms. Snyder (1933) uses the name Salmo irideus for the large-scaled coast rainbow, which he says (p. 102) has scales in the lateral series numbering 120 to 150 or so. Michigan specimens have scales ranging within these limits, only occasional individuals having scale counts near the upper extreme. Many have approximately 135 scales. Snyder (1933, p. 103) uses the name Salmo stonei for the Shasta rainbow (the name shasta is regarded by him as synonymous with stonci, which has priority) and gives the scale count as 150 to 165. Hubbs (1926, p. 16) points out that both the irideus and shasta forms have been propagated in Michigan, with more or less crossing in the hatcheries, but that the irideus form is predominant in the waters. $\mathrm{He}$ regards both forms as subspecies of Salmo gairdnerii (Hubbs, 1929, p. 426). Examination of Michigan specimens taken for scale study has shown low scale counts, with occasional exceptions.

\section{Scale Characters}

The growth of a rainbow trout scale, during any one season, is marked by widely-spaced circuli (ridges) during the earlier part of the season and by narrowly-spaced circuli during the latter part. According to interpretations of workers on salmonoid scales, rapid growth is attended by wide spacing of circuli, while slow growth is attended by narrow spacing of circuli. Bhatia (1931) has experimentally demonstrated that this is true of rainbow trout scales. By feeding fish very heavily he was able to cause very widely-spaced ridges to be formed. Conversely, by starving fish he was able to produce very narrowly-spaced ridges. Major changes in growth rate are reflected in scale structure. The fast growth of early spring and summer may thus be identified on the scales of wild fish from Michigan localities. A zone of slow growth marks the last growth of the season. Fortunately, the winter period leaves a clear record that is not easily confused with minor disturbances in growth rate such as occur among wild fish. 
While the winter mark, or annulus, is recognizable on the scales of Michigan rainbow trout, this is not the only interruption to growth which takes place. A large number of scales had a growth rate interruption or "check" a short distance out from a true winter mark. A specimen with scales in the process of forming such a "check" was taken when transforming to the silvery coloration of the migratory stage. This individual was taken May 27, 1931, in the Au Sable River at Mio. Another specimen taken in Saginaw Bay of Lake Huron on May 29, 1930, proved to have a similar mark close to the margin of the scale. All fish whose scales showed growth interruptions, comparable to these, agreed in having this mark at such distance from the true annulus as to indicate that transformation occurred during late spring. Rich (1920) has presented evidence that scales of young chinook salmon may show a growth-interruption check formed by reason of changes in growth rate with migration from stream to estuary.

Using differences in spacing of circuli, periods of stream growth and lake growth were readily identified on scales of the migratory type rainbows. Catches of fish living in streams and in the Great Lakes allowed verification of the characteristics of both types of growth. Use of mere rapidity of growth as indicative of lake growth may appear questionable, since it may be supposed that some individuals might grow rapidly under stream conditions. Field studies indicate, however, that fish which live in streams throughout life are not able to grow nearly so rapidly as the fish living part of their lives in Lake Michigan, or others of the Great Lakes.

The spawning mark of the rainbow scale, like the corresponding scar on other salmonoid scales, is caused by actual loss of scale material. More of the scale substance is lost from the posterior (exposed) field of the scale than from the anterior (imbedded) field, which is thus a more favorable region for measurement. Loss, probably through absorption, takes place before breeding occurs, while the fish are sleek and show no signs of the destructive changes which often accompany breeding. Resumption of growth following breeding subtends the worn edge of the scale of the breeding fish with new scale material and a permanent scar is recorded. The mark of the first spawning is likely to be less than that of subsequent periods of reproduction and may even be unidentifiable. Males usually have a more severe loss of scale material than females.

Breeding fish do not resume growth until reproductive functions are completed, and are thus later to commence growth in spring as compared to juvenile individuals. Scales of adult breeding fish taken in the Little Manistee River April 11 to 18, 1931, had no new growth, while scales from juvenile fish taken at the same time had added several circuli outside of the recently-formed annulus. The shorter growing season of adult individuals helps to explain a slackening of growth rate after attainment of maturity. 
Measurements of the anterior field of scales were used in calculations of lengths of rainbow trout at various years of life. The direct proportion equation was used: known fish length at time of capture: scale measurement at time of capture: unknown length of fish at end of any one growth season: scale measurement at end of that growth season. The accuracy of this method was tested from measurements of scales from thirty fish in their first season and twenty-five fish in their second season taken from the Little Manistee River on August 22, 1930. According to this material, the calculated lengths of the fish at one year of age, based on measurements made from scales of fish taken in August of the second season, was $7 \%$ too low if the proportion of scale size to fish size was the same in both series. Since the fish grows to some size before scales are formed ("Lee's phenomenon"), lower than true values for calculated lengths for the first year are to be expected. According to Bhatia (1931, p. 49-50), "The rate of growth of the scale relative to the growth of the trout is higher in the earlier stages and proportionate subsequently." The rapid growth of the scale in early life would thus tend to compensate for "Lee's phenomenon." Compensation is indicated by the fact that calculated lengths for fish at the third year were not lower than measured lengths of comparable individuals collected at this age. Fourteen male fish, measured at the end of the third year, when maturing for the first time, averaged 17.51 inches in total length. Seven females averaged 18.60 inches. Calculated lengths for the third year (first year of maturity) based on scale measurements of ten male fish, of the fourth, fifth, sixth and seventh year groups, averaged 19.03 inches. Calculated lengths for the third year (first year of maturity) based on scale measurements of twelve females, of the fourth and fifth year groups, averaged 19.50 inches.

\section{GrowTh TYPES}

The growth rate of the fish was found to differ with the relative amount of time spent in streams as contrasted to lakes. To facilitate comparisons, it seems advisable to divide the material into seven growth types. A simple scheme of classification, similar to that employed by several investigators of salmon and trout, is used. The symbol $a$ designates stream life and $b$ designates lake life. Years are separated by a colon. Spawning marks, when sufficiently well-defined to be noted, are marked by the symbol SM at the beginning of the year at which breeding took place. For example, 2a:a plus b:SM indicates a fish which spent two and a part of a third season in a stream, then migrated into a lake and grew for the remainder of the third season, maturing at the beginning of the fourth season. The 97 adult specimens which were studied fall into the following groups: 
(1) 1a:a: etc. Stream-resident individuals, which do not migrate to a lake but mature in the stream. While only three adult and maturing specimens were studied, it is not uncommon for rainbow trout in certain streams to mature without having access to a lake.

(2) la:a plus b:SM. First growing season in stream: second started in stream, finished in lake: usually breeding at beginning of third. Seven individuals.

(3) $2 a: b: S M$. Two growing seasons in stream: third in lake: usually breeding at beginning of fourth. Eighteen individuals.

(4) 2a:a plus b:SM. Two growing seasons in stream: third started in stream, finished in lake: usually breeding at beginning of fourth. This group is evidently the most frequent one. Sixty-one individuals.

(5) 3a:b:SM. Three growing seasons spent in stream: fourth in lake: usually breeding at beginning of fifth. Four individuals.

(6) 3a:a plus b:SM. Three growing seasons in stream: fourth started in stream, finished in lake: usually breeding at beginning of fifth. Five individuals.

(7) 4a:a plus b:SM. Four growing seasons in stream: fifth started in stream, finished in lake: breeding at beginning of sixth. One individual.

\section{Age-Size Relationship}

The growth rate of non-migratory specimens was more uniform and less rapid, in later years of life, than the growth rate of the migratory individuals. All of the migratory types were featured by rapid rise in the growth rate immediately following establishment of lake residence. The scales of all old specimens showed a slackening of growth rate, the annual growth increment of the year following first maturity being less than that of the year preceding, and subsequent years showing decrease in the growth increment.

The first year of lake growth is quite evidently the year of greatest length increase for these rainbow trout. It is not exceptional for fish to migrate when two years old and seven inches long (total length) and to return after one season in the lake to spawn at nineteen inches.

Female rainbow trout grow at least as fast as males, according to the material studied. Statistical analysis of measurements of large series of specimens would be necessary to determine whether there are significant differences.

\section{Age at Maturity and Longevity}

The specimens which were taken during their first breeding season, together with older specimens which show spawning marks, form the basis for conclusions regarding age at maturity. A few August "parr," taken in streams when in their second growing season, had enlarged reproductive organs and would probably have bred 


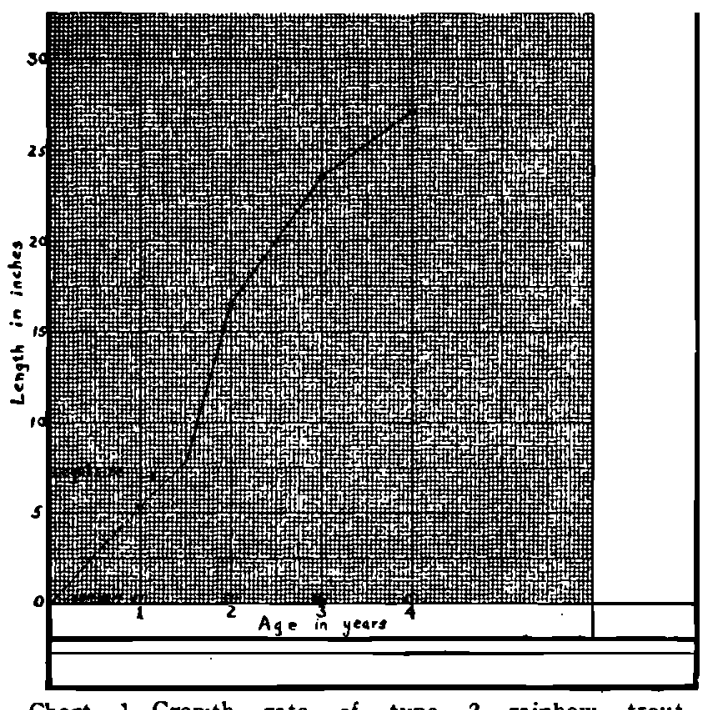

Chart 1 Growth rate of type 2 sainbow trout. (Stream growth shown by dashed line; lake srowth by solid line).

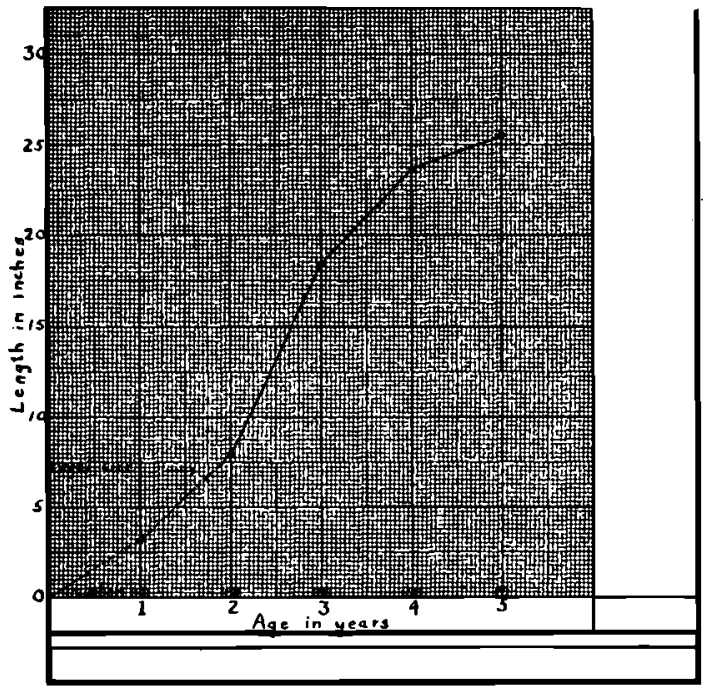

Chart 2 Growth rate of type 3 rainbow trout. (Stream growth shown by dashed line; lake growth by solid line). 


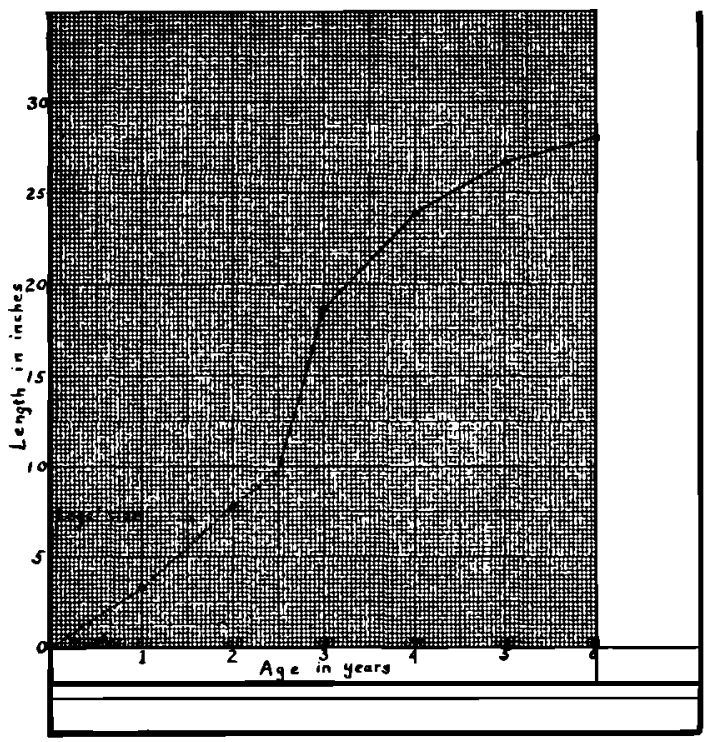

Chart 3. Growth rate of type 4 rainbow trout. (Stream growth shown by dashed line; lake growth by solid line).

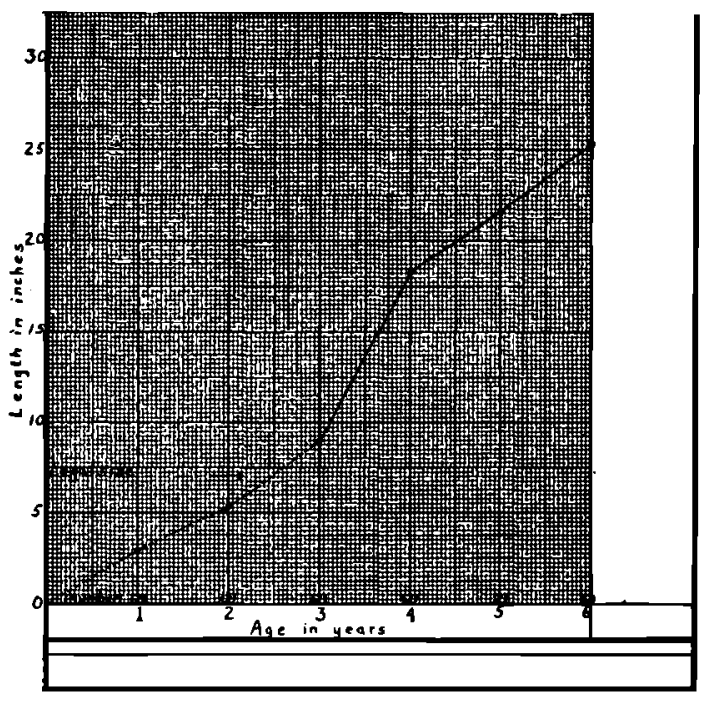

Chart 4. Growth rate of type 5 rainbow trout. (Stream growth shown by dashed line; lake growth by solid line). 


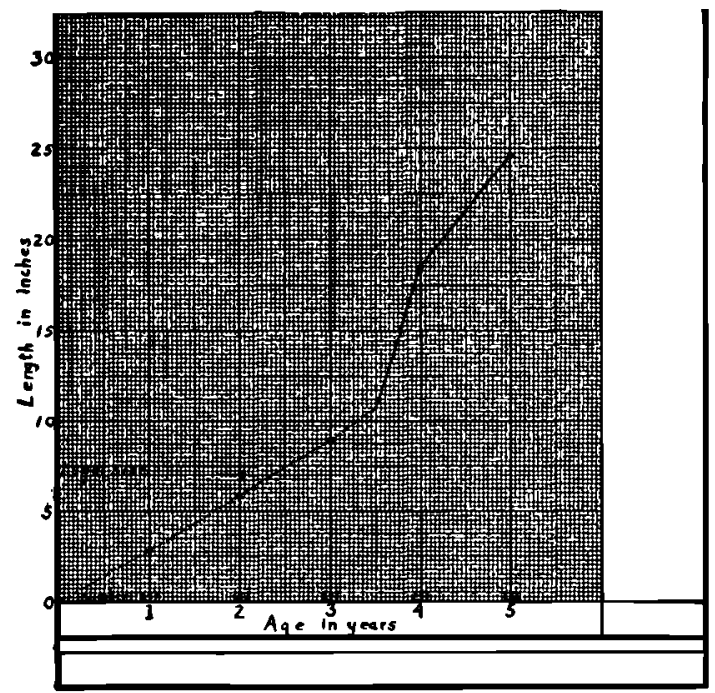

Chart 5. Growth rate of type 6 rainbow trout. (Stream growth shown by dashed line; lake growth by colid line).

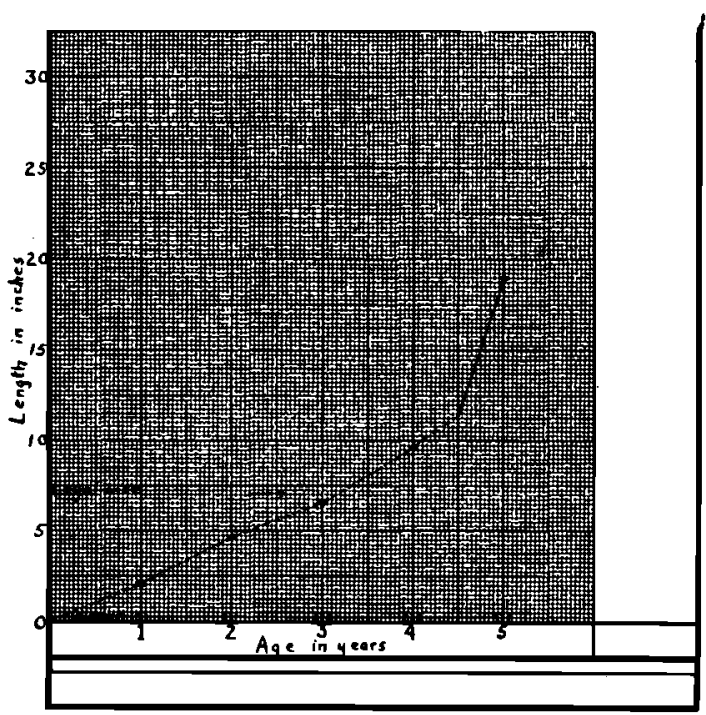

Chart 6. Growth rate of type 7 rainbow trout. (Stream growth shown by dashed line; lake growth by solid line). 
for the first time at the beginning of the third growth season. All such individuals were males. The fish of type 2 , most of which bred for the first time at the beginning of the third growing season, after spending a large part of the second season under the rapid growth conditions of a lake, represent both males and females. Most of the rainbow trout evidently mature for the first time at three years old (beginning of fourth growing season). A few individuals (type 5 , with four individuals) were not mature until four years old (beginning of fifth growing season), while one individual (type 7) did not mature until five years old (beginning of sixth growing season).

Conclusions regarding longevity are warranted when the material studied represents the oldest year-classes which exist. Whether or not there are older fish in Michigan waters than are represented in the material studied is somewhat uncertain. Care was taken to select, from among approximately one thousand individuals held at the Junction Dam station during May, 1931, several of the largest individuals of both sexes. The largest individuals found here (31 inches for both males and females) agreed very closely with the estimated maximum sizes of many hundreds of individuals seen on spawning grounds of the Pere Marquette, Little Manistee, Manistee and Platte Rivers during 1931 and 1932. Individuals larger than the largest ones studied are very scarce in these waters, if they do exist (which is not improbable).

The oldest fish examined were seven winters old. Both of these fish were males. Six males a year younger were included in the series of fish studied. Fish of five winters were frequent; twentytwo specimens representing both sexes were studied. None of the females seen were older than five winters.

The greatest number of breeding years was three for females and four for males (except for one individual evidently representing a fish breeding five times). The possible existence of a longer life and a greater number of breeding years for males as compared to females among wild rainbow trout is suggested by the present study. Observations on spawning grounds indicate that males are more numerous than females. Also, the largest males are of larger size, on the average, than the largest females. The polyandrous mating, two males mating with one female (Greeley, 1932), is suggestive that there may be a correlated greater number of breeding seasons for males.

\section{Growth Rate in Relation to Angling Value}

When living under a combined stream and lake habitat, as is the general rule with the rainbow trout in Michigan, this fish grows very rapidly. The angling value of the rainbow resource is affected by the rapidity of growth, for the quicker the growth, the quicker the taking of legal fish becones possible provided availability remains the same. The duration of stream life affects availability, for 
the fish are far more likely to be caught by anglers when they are living in streams rather than when scattered over a large water area of the Great Lakes. An individual fish is exposed to legal capture only when it attains legal size ( 7 inches) before migration into other waters or when lake life is spent in a lake that may be effectively fished by angling or when it returns to a stream and remains there during a part of the open season.

Some Michigan streams have rainbow trout which do not migrate and these fish have the highest probability of being available throughout life. The "parr" of other rainbow support a large amount of angling. for many of them reach legal size before migration. According to calculated lengths at time of migration for ninety-six rainbows of migratory growth types, ninety-one per cent had reached legal size by the time of migration. In interpretation of the significance of this rather high percentage, however, it should be borne in mind that to be available to anglers, fish must have reached legal size by the end of the open season just before migration, provided their journey was started before the beginning of the next open season. The predominant class, type 4 , is made up of fish which migrate during the spring. The average calculated length at migration of the 61 individuals of this group was 9.8 inches (extremes 7.3-13.1 inches). While all of these fish were legal at time of migration, a greater or less number probably were below legal size at closing of the season (September) previous to migration. In certain streams, the percentage of rainbow "parr" which reach legal size at the end of two seasons of growth is not large. A series of 102 fish taken in the Little Manistee river from August 8 to 22,1930 , at the age of one winter (in second growing season) had but 26.2 per cent of fish over legal size. While the sample was doubtless affected by angling, which removed a number of the larger fish, yet it indicates that in this stream a large percentage of rainbow parr are unavailable for angling or are available for but a very short period before migration. The availability of migratory rainbow trout, in Michigan waters, depends, to a large degree, upon the rapidity of growth during the "parr" stage.

\section{Bhatia, D.}

\section{LITERATURE CITED}

1931. On the production of annual zones in the scales of the rainbow trout (Salmo irideus) 1. Journ. of Exper. Zool., Vol. 59, No. 1.

Greeley, J. R.

1932. The spawning habits of brook, brown and rainbow trout and the problem of egg predators. Trans. Amer. Fish. Soc., Vol. 62.

Hubbs, C. L.

1926. A check-list of the fishes of the Great Lakes and tributary waters with nomenclatorial notes and analytical keys. Univ. of Mich. Museum of Zoology, Misc. Publ. No. 15. 
1929. Further additions and corrections to the list of the fishes of the Great Lakes and tributary waters. Mich. Acad. Sci. Arts and Letters, Vol. XI.

Rich, W. H.

1920. Early history and seaward migration of Chinook salmon in the

Columbia and Sacramento rivers. Bull. U. S. Bur. Fish., Vol. 37. Snyder, J. O.

1933. California trout. California Fish and Game. Vol. 19, No. 2.

In the following tables adult fish are marked by an asterisk (*) following the $\operatorname{sex}(M$ or $F)$.

\section{TABLE 1}

Measured total lengths in inches of rahbow trout of 0 Winter growp

\begin{tabular}{|c|c|c|c|c|}
\hline Loeality & Date & No. & $\mathbf{A v}$ & Bxtremes \\
\hline $\begin{array}{l}\text { Little Manistee } \\
\text { Little Manistee } \\
\text { Little Manistee } \\
\text { Little Manistee }\end{array}$ & $\begin{array}{l}\text { Rlver_-August } 2,1930- \\
\text { River._August } 8,1930 \\
\text { River._. August } 18,1930 . \\
\text { River._August } 22,1930 \ldots\end{array}$ & $\begin{array}{r}1 \\
4 \\
30\end{array}$ & $\begin{array}{l}2.63 \\
2.30 \\
3.64 \\
2.98\end{array}$ & $\begin{array}{l}1.75-3.56 \\
3.31-3.81 \\
1.89-3.69\end{array}$ \\
\hline
\end{tabular}

TABLE 3

Calculated total lengths in Inches of rainbow trout of II winter group

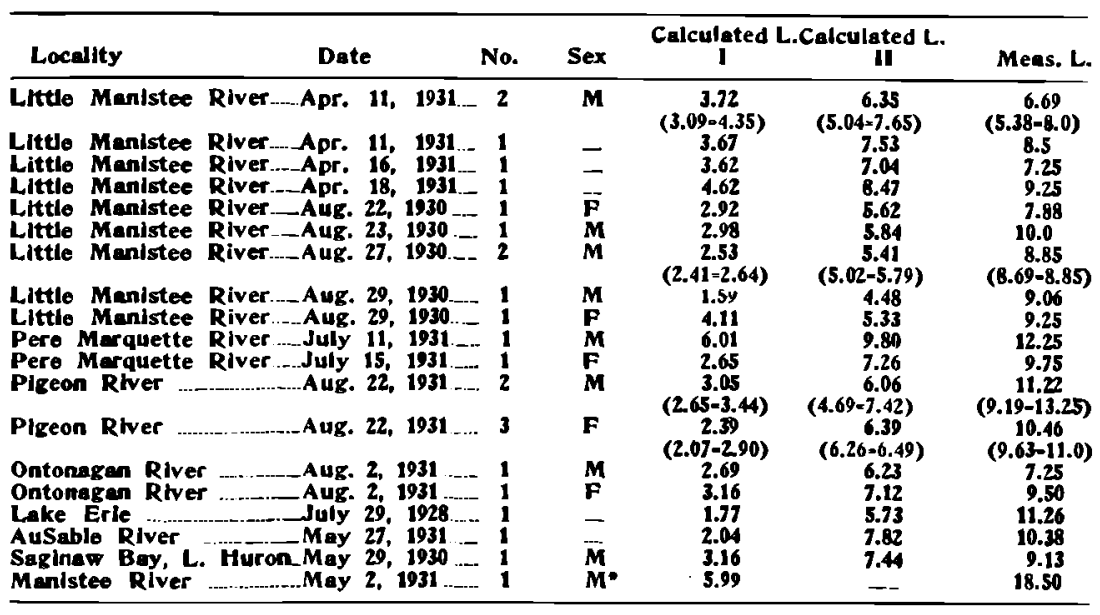


TABLE 2

Calculated totel lengths in inches of rainbow trout of 1 whiter group

\begin{tabular}{|c|c|c|c|c|c|}
\hline Locallty & Date & No. & Sex & Calculeted L. & Measured L. \\
\hline 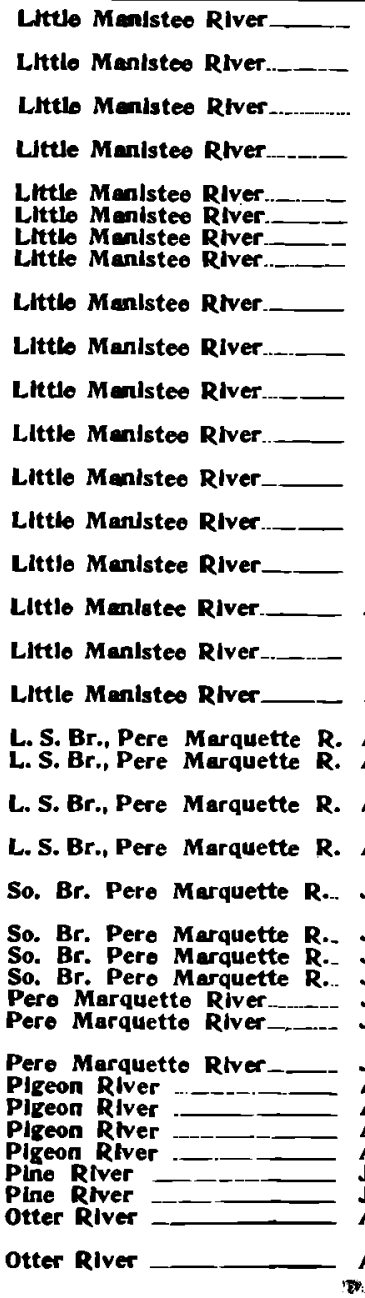 & 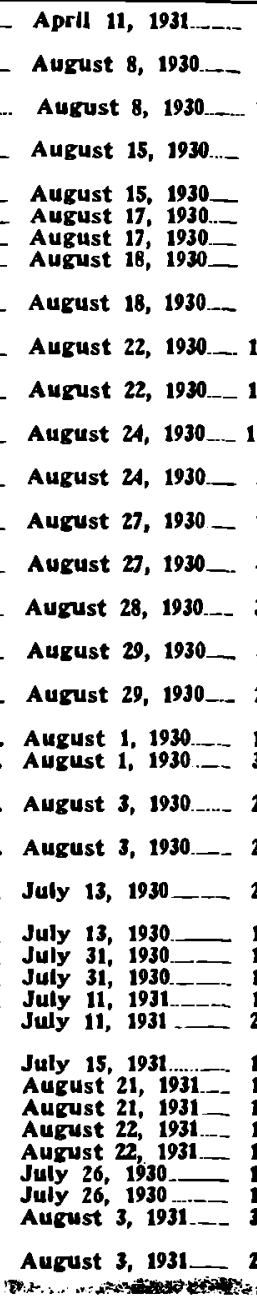 & 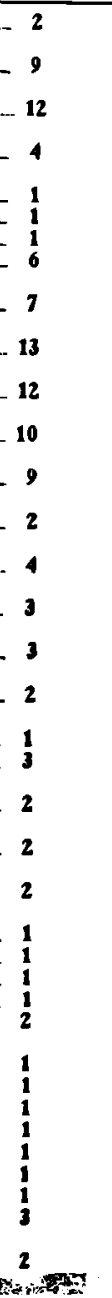 & $\begin{array}{l}\mathbf{M} \\
\mathbf{F} \\
\mathbf{M} \\
\bar{M} \\
\mathbf{P} \\
\mathbf{M} \\
\mathbf{P} \\
\mathbf{M} \\
\mathbf{P} \\
\mathbf{M} \\
\mathbf{F} \\
\mathbf{M} \\
\mathbf{M} \\
\mathbf{P} \\
\mathbf{M} \\
\mathbf{P} \\
\mathbf{M} \\
\mathbf{F} \\
\mathbf{M}\end{array}$ & 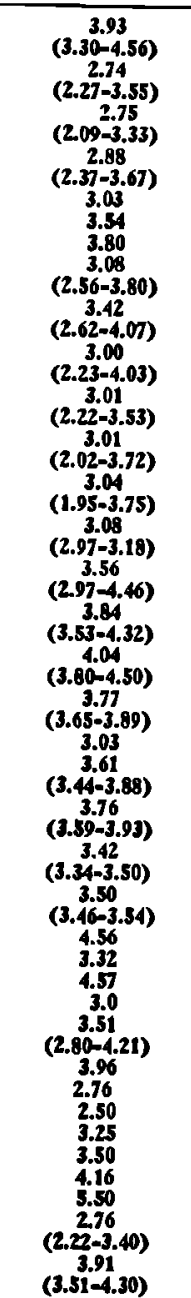 & $\begin{array}{c}4.75 \\
(4.13=5.38) \\
5.73 \\
(4.88-6.38) \\
5.79 \\
(5.0-7.13) \\
6.24 \\
(5.50-7.13) \\
5.50 \\
7.63 \\
7.25 \\
6.37 \\
(5.38-7.13) \\
6.56 \\
(5.75-7.38) \\
6.15 \\
(4.94-7.06) \\
6.30 \\
(4.81-7.31) \\
6.31 \\
(5.06-7.25) \\
6.30 \\
(4.56-7.63) \\
6.29 \\
(6.19-6.38) \\
6.63 \\
(6.06-7.88) \\
7.40 \\
(7.06-7.63) \\
8.19 \\
(7.25-8.75) \\
7.70 \\
(7.06-8.34) \\
6.19 \\
6.94 \\
(5.63-7.68) \\
8.07 \\
(8.0-8.13) \\
7.13 \\
(7.007 .25) \\
8.38 \\
9.0 \\
6.75 \\
7.89 \\
7.0 \\
7.63 \\
(7.0-8.25) \\
9.0 \\
9.06 \\
6.50 \\
8.31 \\
8.31 \\
7.58 \\
9.0 \\
5.88 \\
(5.13-6.38) \\
6.72 \\
(6.19-7.25)\end{array}$ \\
\hline
\end{tabular}




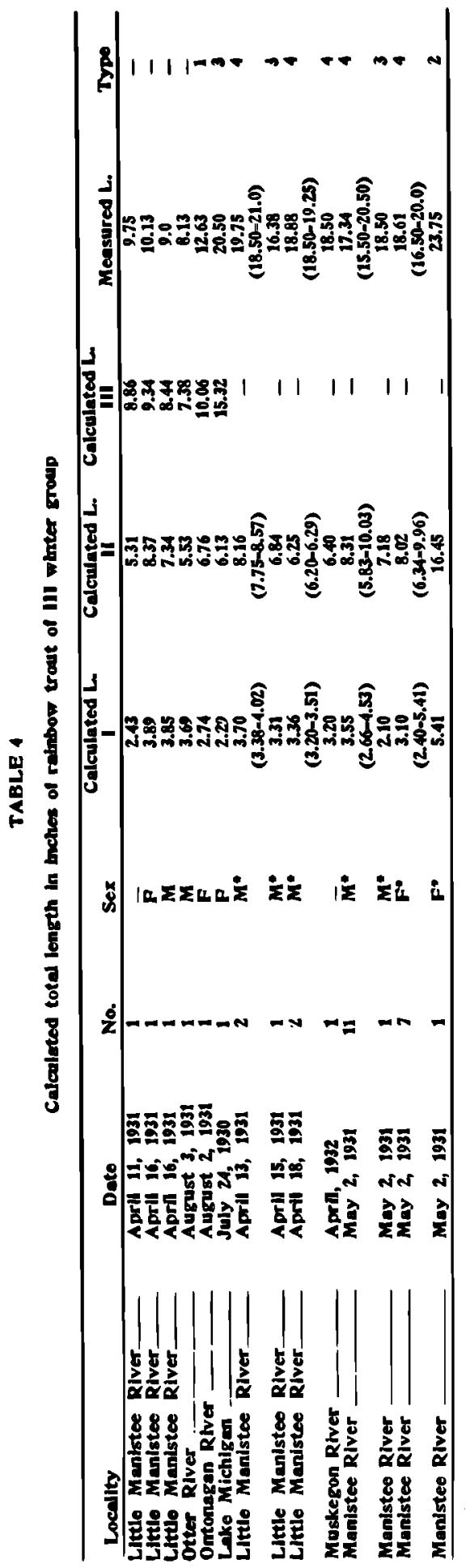

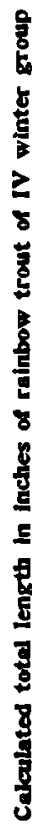

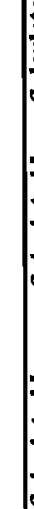

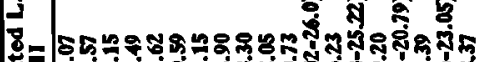
= 8

$211111^{80}$

8

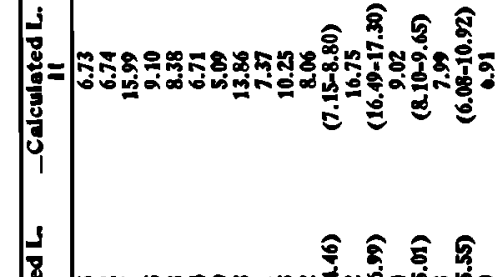

8. 造

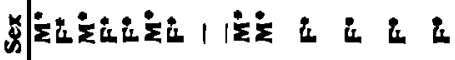
s

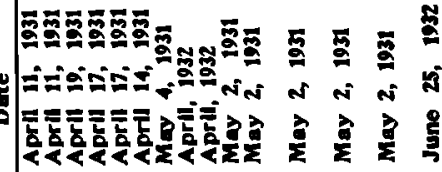

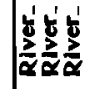
过 를 . 

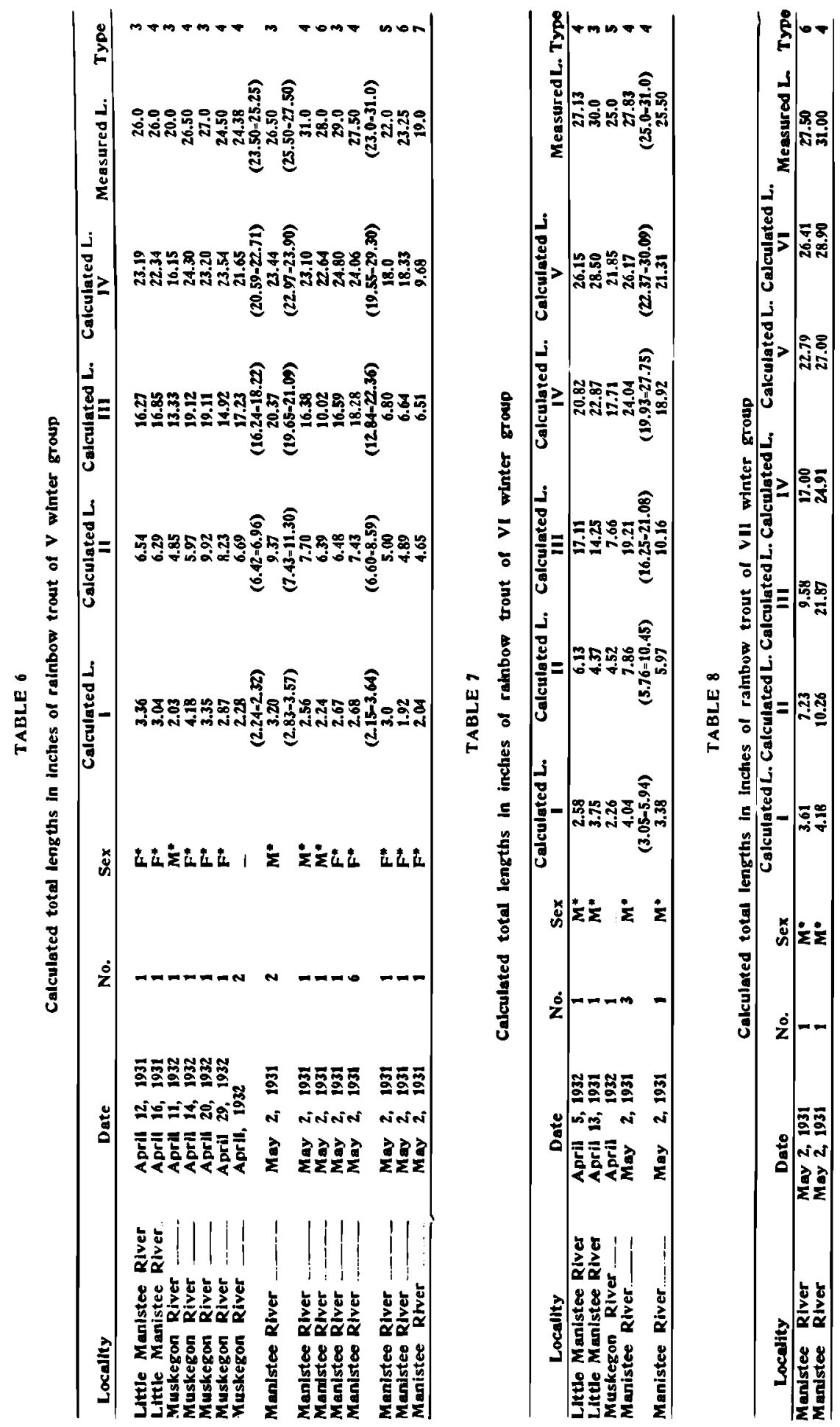


\title{
Discussion
}

\author{
(Illustrated by slides.)
}

Mr. Tunison: Have you had occasion to determine the growth rate of sea trout that have been kept in a stream for five or six years and then went out to the lakes? Do you get an acceleration of growth when they are about six or seven years old?

DR. GREELEY: I have not the material that would establish that, but the rapid year of growth is the year just before maturity-that is when you get the steepest climb. These rainbows go into Lake Michigan, where there is rich food and a big range, as immature fish, and they climb very rapidly in growth rate and then slacken up later. A point I neglected to mention in that connection is that the reproductive organs take a great deal of growth from the fish, that is, metabolism has to take account of the maturing reproductive organs. That is clearly illustrated by getting a series of rainbows in April, as I did on the Little Manistee River; the non-bred fish had already begun growth by April of that year, while the bred fish did not form the winter mark until they got through spawning. In some species in the same locality you get the winter mark at different times, according to whether they are mature or immature. Naturally the older fish is slackening in growth rate.

Mr. Tunison: I was wondering whether a study of the trout over a period of three or four years would show any substantial acceleration in growth at that late age. I think it has been shown by some authorities that you can get that acceleration.

Mr. Markus: I understand that the fish you took the scales off after they were seven years old were hatchery fish?

Dr Greeley: They were wild fish. At that time a great number of rainbow trout were propagated from wild eggs taken from the spring run of these fish into the Muskegon River and into the Manistee River. This particular place was on the Manistee. These were Lake Michigan wild fed fish.

Mr. Marzus: You have no idea, then, as to the actual number of years in the case of these fish, other than the scale count?

DR. GREmeY: Nothing except what is general knowledge in the hatcheries of the time at which the rainbow matured; these results checked quite nicely there. As to the greatest length of life, there are one or two published records of rainbows living seven or eight years, but we have very little definite information on individual fish to show how long they can be kept in the hatchery without dying off. Even if you did have that for the hatchery, I do not know whether it would apply to wild fish making their migration before going through the spawning process.

Mr. Markus: I should like to see the scales of a hatchery fish that has been fed continuously and see what the annuli look like on those scales.

Dr. Greney: According to this British investigator, Bhatia, a fish can be fed right over the winter and no annuli are produced if they are fed well.

Mr. Markus: That is exactly what I expected. 
DR GREetey: It shows you can use scales for growth determination only when they have stopped growing in the winter.

Mr. Russ: Dr. Greeley stated in his talk that he had male rainbows three years old maturing for the first time. Doesn't he find that these males mature earlier than that?

Dr. Grentey: I mentioned I had fish of one growth type which matured in two years. I had fish in that growth type which spent only one and a fraction years in the stream and then migrate to the lake and make a rapid growth, maturing at two years. The increase in the first year after migration is from six, seven and eight inches up to eighteen, nineteen or twenty inches-that is the season just before they mature. But I had males taken in the streams at August of their second year which in their reproductive organs gave indications of going to mature at two seasons without migrating to the lake. So that I think among your non-migratory rainbow you may find, in your wild fish, a number which mature at two seasons rather than three.

Mr Russ: I asked this question because I have used rainbows at eighteen months-males-that were absolutely satisfactory for breeding purposes.

Dr. Greeley: Were they selected at all?

Mr. Russ: Yes sir.

DR. OSBURN: Is there a considerable difference in the rate of growth between the fishes that live in the streams and do not migrate and those that do migrate into the lakes?

Dr. Greeley: There was a considerable growth rate difference between rainbow, say four years old, which stayed right in the stream and those which had migrated, even when those in the stream were mature fish. I have seen rainbows as small as fourteen and fifteen inches that were over four years old. I have other fish which are only three years old and are nineteen or twenty inches long which migrate. Rapid growth is correlated with range in the Great Lakes just as it is in salmon; they do not grow fast until they get to the ocean.

DR. WIEBE: What would be the picture of the scale if a fish had abundant food for a month or two early in the season, then was starved for the next two months, and then was fed again heavily for a few months after that?

Dr. Gremey: I should think experimental work done on that would give a pretty good clue to what it would be like. But this particular work was not starving and then feeding and then starving and feeding the same fish. When it is done twice on a fish you get that apparent winter mark forming-it looks almost like a winter mark-because the fish has slackened its growth. In other words, what we are determining in fish growth rate investigations is growth cessation mark. The only way we can be sure it is a winter mark is to prove that in a given species they do not slacken in growth at some other period.

Dr. Wrabe: The reason I asked that question is this: A couple of years ago I submitted some scales from bass of which we had the absolute age to 
within a week or ten days, and these determinations by scale experts disagreed all the way from fifty to one hundred per cent.

Dr. Greeley: I can see how that might well be, because you cannot be sure of ages in fish by just taking every interruption in circuli pattern as a year mark. The only reason $I$ am sure of my year marks on these rainbows is that they grow in a regular way. They do not have any occasion to stop growing in the middle of the year; they go to Lake Michigan and they keep right on through. By the time they transformed to the smolt or migratory stage they had formed a little check, showing they were interrupted. In the case of Pacific salmon that migrates you have that same thing; and also in the change from hatchery fish, planting them in the wild stage a little time before they can find food, it is registered on the scale. The scales are extremely delicate.

Mr MARKus: I would like to know how you determine the difference between these checks of growth during the winter or summer.

Dr. GReEley: The only check we have on the rainbow spring migration markis that the one you have reference to, the time at which they transform?

Mr. Markus: What I mean is, how do you know the winter annulus from checks, during the growing season.

Dr. Grenley: There are no permanent checks during the growing season on these fish that I have here; also in the adult fish they form a definite spawning mark which is an erosion of the scale. I have a couple of photographs here which, I think, will perhaps save a good deal of explanation on that spawning mark. But at the time we stopped the year's growth the fish spawned along in April before beginning another year's growth, so that there is a heavy erosion of the scale at the end of a year's growth. That checks very nicely, and there is nothing at all in the way of minor interruptions; you are not bothered in these scales with minor interruptions of growth. You find the scale goes right on ahead until the regular slowing down of growth in the fall, and you get a very nice winter mark formed. You can catch fish in, say May and June, which have a winter mark near the meridian just above the circuli or in the growth around it, or you can catch fish right at that time which have a little margin, which checks with where you would expect it. The migration annulus is never very fas out from the year's mark preceding it, because the fish which split a year between lake and stream are usually out of the stream by early May and they have only a few weeks spring growth before they migrate. If you calculate length, you find that fish will grow three inches in one winter and seven inches in the next and about nine inches at the time they migrate.

Mr. Markus: You do not happen to have slides which will show that?

DR. GREELEX: I have two photographs that show the migration interruption, the mark I have called migration check.

Mr. Marxus: I should like very much to see that pointed out.

Mr. Terresl : How long a time expired between each of these lines or circuli? 
Dr. Greeley: I cannot say as to that, but I think the work of the British investigator, Bhatia, does show that I have not the information at hand, but the circuli are nothing more than ridges, just about the same as ridges on a thumb print or finger mark, and as the scale gets bigger, more of these ridges are added. The number of ridges added would be in proportion to the amount of scale material there. That point is discussed in that particular paper.

The President: In this connection I may say that in the coastal streams of California and Oregon, in which of course the steelhead is native, it has been found that some of the young steelheads remain jin the stream for approximately a year before going to sea, but some remain two years and some three. There is evidence to show, although I do not think it can be said to be demonstrated yet, that in some cases they may not go to sea at all but remain permanently in fresh water. Of course, I refer now to streams in which they have ready access to the sea if they desire to go there.

In connection with the early maturity of the rainbow trout in the hatcheries, I suspect that something of that may be correlated with the rapidity of growth. At our experimental hatchery at Pittsford, we have a stock of rainbows in which the first generation all matured at three years. We selected from among the most rapidly growing fish in the lot and in the next generation a few of them matured at the end of the second year, although the majority matured the third year. It was seen, therefore, that there was some correlation between rapidity of growth and early maturity; that is certainly the case with brook trout, as I think you are all aware. 


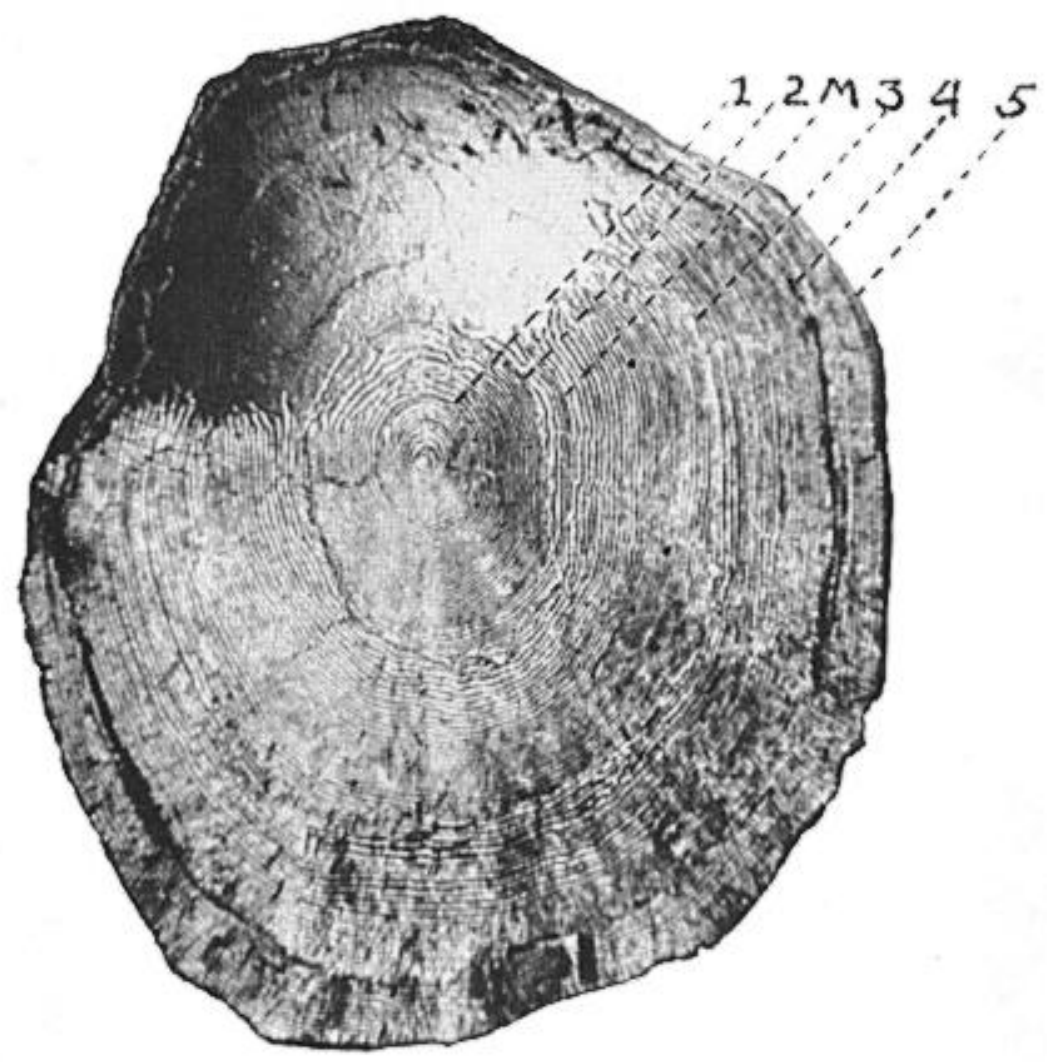

Scale of adult iemale rainbow trout, total length $291 / 2$ inches, from Manistee River, Vay $2,19.31$. (ilculated lengths (inches): 2.76 at first annulus (1): 792 at second ammulus (2); 9.21 al migration check (M); 18.43 at third annulus (3); 25.99 it iourth annulus (4). The scale shows spawning marks at 4 th and 5 th annuli. 